\title{
Assessment of Aurora A kinase expression in breast cancer: A tool for early diagnosis?
}

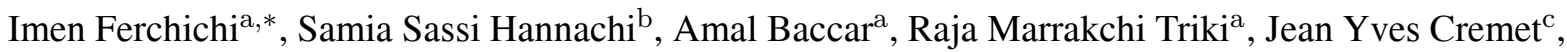 \\ Khaled Ben Romdhane ${ }^{\mathrm{b}}$, Claude Prigent ${ }^{\mathrm{c}}$ and Amel Ben Ammar El Gaaied ${ }^{\mathrm{a}}$ \\ ${ }^{a}$ Laboratory of Genetics, Immunology and Human Pathology, Department of Biology, Faculty of Sciences of Tunis, \\ Tunis, Tunisia \\ ${ }^{\mathrm{b}}$ Department of Histopathology, The Oncology Institute of Saleh Azaïez, Bab Saadoun, Tunis, Tunisia \\ ${ }^{\mathrm{c}}$ The Institute of Genetics and Development of Rennes, UMR 6061, Rennes Cedex, France
}

\begin{abstract}
Aurora A kinase is overexpressed in many cancers but the status of this protein in the breast cancer often varies. We investigate the expression and localization of Aurora A protein in relation with tumor emergence and progression in breast cancer. Aurora A kinase status was evaluated in 107 patients using immunohistochemistry. The experimental findings showed that high expression of the Aurora A protein was correlated with elevated nuclear grade, low expression of progesterone receptor and positive nodal status. The experimental results showed also that the localization of this kinase shifts from cytoplasm in non malignant adjacent tissue to both cytoplasmic and nuclear compartments in tumoral tissue, suggesting an oncogenic role of the nuclear accumulation. We have, furthermore, detected the overexpression of this protein in non malignant adjacent tissue. The expression of the Aurora A kinase in non malignant tissue may represent an earlier diagnosis tool for breast cancer.
\end{abstract}

Keywords: Aurora A, breast cancer, immunohistochemistry

\section{Introduction}

The Aurora A protein is a Serine/Threonine kinase, with 403 amino acids and 46 kilodaltons (Kda) as molecular weight [1]. This kinase plays a crucial role during mitosis [2,3]. It acts as a key regulator of multiple mitotic events: centrosome maturation and separation [4], regulation of spindle assembly [5,6], equal segregation of chromosomes and cytokinesis [7]. Aurora $\mathrm{A}$ is a cell-cycle regulated protein [8], and this centrosome-associated kinase is active and expressed at a high level during G2-M phases [9-11]. This protein is degraded at the end of mitosis [12-15]. In normal tissue Aurora A is restrained to the centrosomes while in late phases of mitosis it is located at the spin-

*Corresponding author: Imen Ferchichi, Laboratory of Genetics, Immunology and Human Pathology, Department of Biology, Faculty of Sciences of Tunis, Tunis 1060, Tunisia. Tel.: +216 275054 51; Fax: +216 71231 401; E-mail: science.biologique@yahoo.fr. dle poles. Overexpression of this kinase alters centrosome number and function leading to aberrant mitotic spindle, missegregation of chromosomes and cellular transformation [16]. Errors in the mitotic process are considered to be one of the major causes of genetic instability that hallmarks cancer [17].

Hence Aurora A is an oncogenic protein encoded by the oncogene STK 15 located on chromosome 20q13.2, which is a highly amplified region in various human tumors such as the esophageal squamous cell carcinoma [18], the colorectal carcinomas [19], the ovarian and gastric cancers [21], human gliomas [22] and breast cancer $[23,24]$. Moreover, mRNA of STK15 is reported to be enhanced in various cancers [23-26]. Polymorphisms in this gene are associated with increased risk of several cancers [27-31] particularly in breast cancer [32].

Aurora A protein is frequently overexpressed in several human cancers: lung [33], head and neck [34], ovarian [35,36], colon [37], prostate [38], pancr- 
eas [39], esophagus [40] and breast one [41], as shown by immunohistochemistry (IHC).

In breast cancer, aneuploidy (abnormal number of chromosomes) is highly prevalent, probably associated with Aurora A; which has been initially identified as BTAK: Breast Tumor Amplified Kinase [1,42]. Breast cancer is the most common type of cancer for women, it's a hormone related tumor with various grade and stage presentations. Some studies were conducted to assess rate expression of Aurora A protein and to reveal its role in breast cancer [41,43-45]. The aim of this study is to investigate the expression level and subcellular localization of Aurora A and to establish if there is any relationship with clinical variables in breast cancer.

\section{Materials and methods}

\subsection{Clinical tissue sample}

107 archival paraffin-embedded tumor sections were collected at the Oncology Institute of Saleh Azaïez (ISA). They have been obtained from patients who underwent surgery with pathologically confirmed breast cancer, and admitted to the institute between 1999 and 2010. The following clinical data were collected: age, histological subtype, tumor grade (SBR: Scarff Bloom and Richardson) tumor size, progesterone and estrogen receptors expression (RP, RE), nodal status, nuclear grade and finally, mitotic index. The patients' characteristics are shown in Table 1. The study protocol was approved by the head of the department of histopathology at the ISA institute.

\subsection{Antibodies}

For this study we used the 6F11 monoclonal antibody for Estrogen Receptor (Novocastra Laboratories, UK) and the PgR636 monoclonal antibody for Progesterone Receptor (Novocastra Laboratories, UK). For Aurora A protein detection we used a mouse monoclonal antibody (clone 35c1), which was developed against the non catalytic N-terminal domain of the kinase; this clone was tested on several breast cancer cell lines: MCF-7, S68, T47D, MDA-MB-468 and SK-Br-3, at the UMR6061 in the Institute of Genetics and Development of Rennes, France [46].

\subsection{Western blot}

The specificity of the Aurora A antibody has been tested on different human cell lines lysates: Hek 293,
Table 1

Patient characteristics $(n=107)$

\begin{tabular}{|c|c|}
\hline Characteristic & $\begin{array}{l}\text { Number of } \\
\text { patients [\%] }\end{array}$ \\
\hline \multicolumn{2}{|l|}{ Age [years] } \\
\hline Median & 45 \\
\hline Range & $24-85$ \\
\hline \multicolumn{2}{|l|}{ Histological subtype } \\
\hline Invasive ductal carcinoma & $95[88.8]$ \\
\hline Lobular carcinoma & $8[7.5]$ \\
\hline Other histology & $4[3.7]$ \\
\hline \multicolumn{2}{|l|}{ SBR } \\
\hline I & $15[14]$ \\
\hline II & $50[46.7]$ \\
\hline III & $42[39.3]$ \\
\hline \multicolumn{2}{|l|}{ Tumor Size } \\
\hline $\mathrm{T} 1[<20 \mathrm{MM}]$ & $14[14.2]$ \\
\hline $\mathrm{T} 2[\geqslant 20 \mathrm{MM}$ and $\leqslant 50 \mathrm{MM}]$ & $72[72.7]$ \\
\hline $\mathrm{T} 3[>50 \mathrm{MM}]$ & $13[13.1]$ \\
\hline Unknown & 8 \\
\hline \multicolumn{2}{|l|}{ Receptor status } \\
\hline $\mathrm{RE}+\mathrm{RP}+$ & 38 [56.7] \\
\hline RE- RP- & $17[25.4]$ \\
\hline $\mathrm{RE}+\mathrm{RP}-$ & $7[10.4]$ \\
\hline RE- RP+ & $5[7.5]$ \\
\hline Unknown & 40 \\
\hline \multicolumn{2}{|l|}{ Nodal status } \\
\hline $\mathrm{N}+$ & 56 [70.9] \\
\hline $\mathrm{N}-$ & $23[29.1]$ \\
\hline Unknown & 28 \\
\hline \multicolumn{2}{|l|}{ Nuclear grade } \\
\hline I & 16 [15.7] \\
\hline II & $55[53.9]$ \\
\hline III & $31[30.4]$ \\
\hline Unknown & 5 \\
\hline \multicolumn{2}{|c|}{ Mitotic index [nb of mitotic cell/ $10 \mathrm{HPFs}^{+}$] } \\
\hline $1[0-5]$ & $40[41.0]$ \\
\hline $2[6-10]$ & $24[35.0]$ \\
\hline $3[>11]$ & $33[34.0]$ \\
\hline Unknown & 10 \\
\hline
\end{tabular}

${ }^{+}$HPFs: high-power fields.

Hela, $\mathrm{RCC}^{+}{ }^{+}$and $\mathrm{RCC}^{-}{ }^{-}$(ATCC, USA), and also on the recombinant human His-Aurora A protein experienced with an increasing concentration. Lysate from each cell line was separated by $12 \%$ SDSPAGE, and the migration was made, in parallel, with the molecular weight standards (low range, Bio-Rad Laboratories, CA); then we transferred separated proteins to nitrocellulose membrane (Hybond Amersham, GE Healthcare, UK). The membranes were blocked in 5\% skim milk in a TBS-T. We probed with the Aurora A antibody in $2.5 \%$ skim milk in a TBS-T. Finally, we incubated with a secondary antibody: peroxidase-conjugated secondary mouse antibody (Jackson ImmunoResearch Laboratories,UK). The protein band was visualized by enhanced chemiluminescence (ECL) (Amersham Pharmacia Biotech, FR) West Pico or Dura (Pierce, Rockford, IL). 

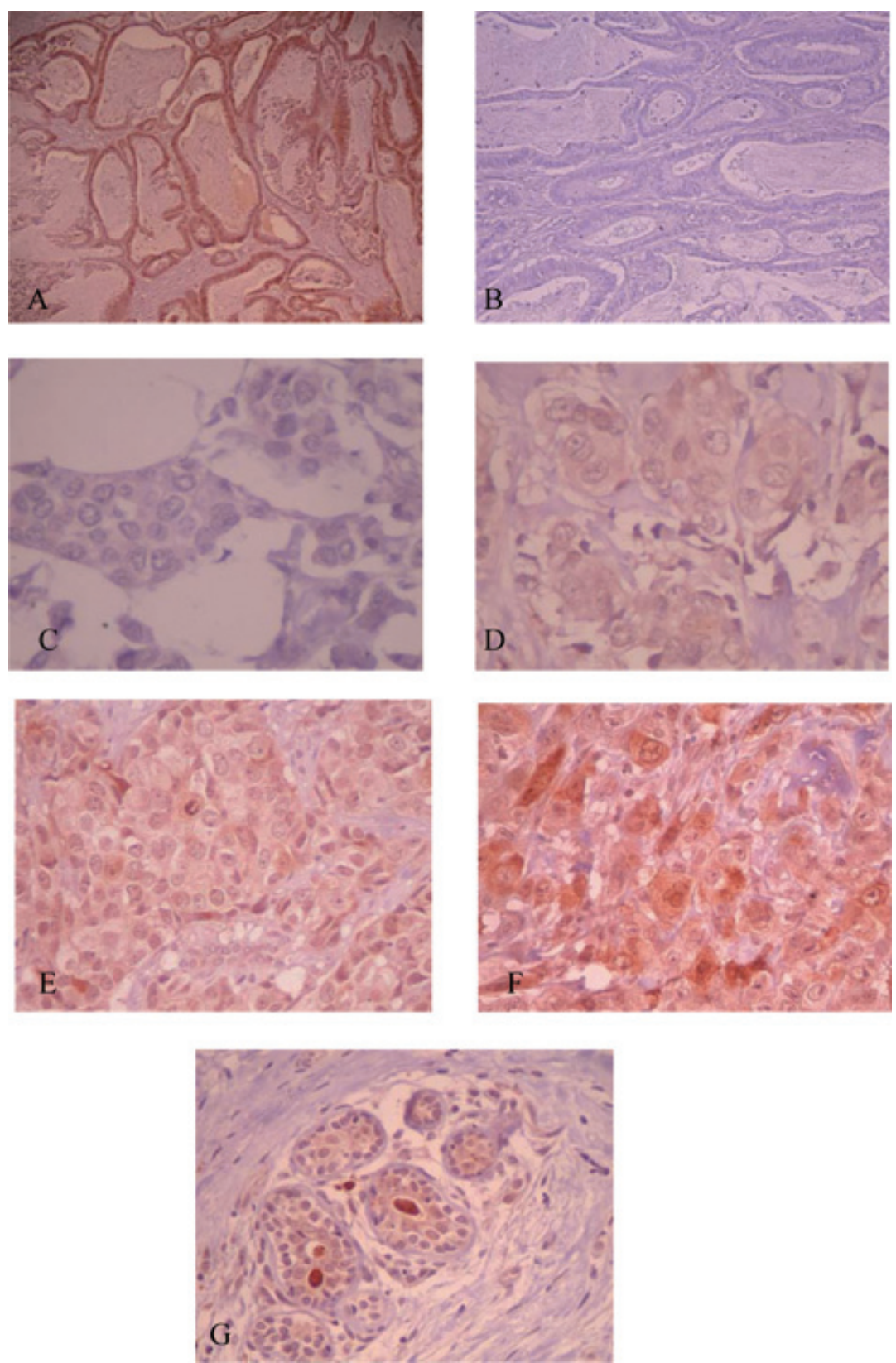

Fig. 1. A and B: Immunostaining of colorectal carcinoma (x400): (A): with anti-Aurora-A antibody: positive control, (B): without anti-Aurora-A antibody: négative control. C, D, E and F: Aurora-A immunostaining in human mammary malignant tissue (x400), brown color indicates antibody binding and intensity of staining is: (C): 0 negative staining, (D): +1 weakly positive staining, (E): +2 moderately positive staining, (F): +3 strongly positive staining. G: Aurora-A immunostaining in lobular mammary non malignant tissue (x400). By using the autologous antibody of Aurora-A protein on a histological section of non malignant lobular mammary, adjacent to the tumor tissue, we observe a staining of this protein in the cytoplasm. (Colours are visible in the online version of the article; http://dx.doi.org/10.3233/DMA-120947)

\subsection{Immunohistochemical staining}

$3 \mu \mathrm{m}$ sections were prepared for each case and afterwards stained with Hematoxylin Eosin (H\&E), intended for histological examination. When the patient's condition requires further investigation, estrogen and progesterone receptors status (ER and PR) were determined.

Briefly, we deparaffinized sections in xylene and we rehydrated them through graded alcohols, then we used 


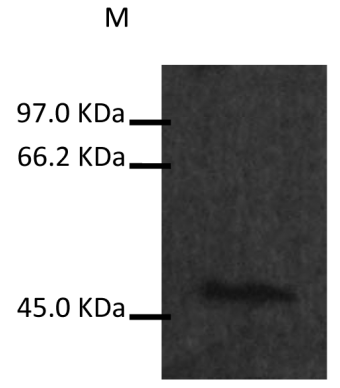

1

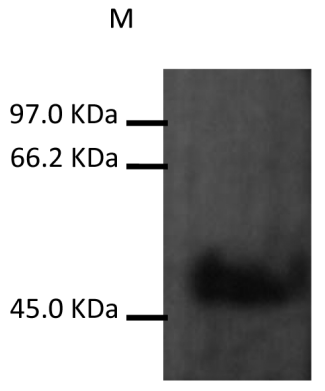

2

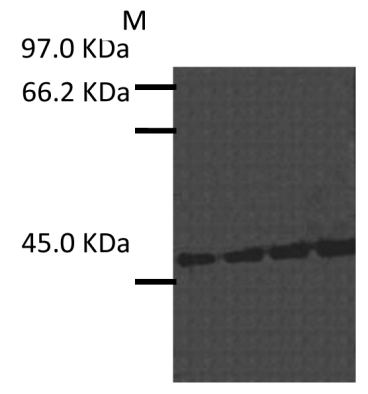

$3 \quad 4 \quad 5 \quad 6$

[c]

Fig. 2. Western blots with the $35 \mathrm{C} 1$ antibody on cell line and purified recombinant human His-Aurora-A protein. (a) lane 1: Hek 293 cells; (b) lane 2: Hela cells; (c) with increasing concentration of the recombinant protein His-Aurora-A: lane 3: 0,25 $\mu \mathrm{g}$, lane 4: 0,5 $\mu \mathrm{g}$, lane 5: 0,75 $\mu \mathrm{g}$, lane 6: $1 \mu \mathrm{g}$, lane M: Protein molecular weight markers.

Table 2

Details about slides $(n=107)$

\begin{tabular}{lc}
\hline Type of the tissue & Number of slides \\
\hline DCIV + IS + Non malignant tissue & 54 \\
DCIV + Non malignant tissue & 33 \\
DCIV + IS & 5 \\
DCIV & 11 \\
IS + Non malignant tissue & 4 \\
\hline
\end{tabular}

a Novolink polymer detection system (RE7150-K, Leica, TN) as recommended in the instruction manual. The slides were incubated with the primary antibody Aurora A at 1:50 overnight in a humidity tray; and a slid of colorectal carcinoma was included in each batch as a positive control for Aurora A (Fig. 1A). A negative control was performed by omitting the primary antibody and did not produce any visible background staining (Fig. 1B).

The evaluation used for intensity of staining and subcellular localization was performed in a blinded manner. Intensity was scored from 0 : no staining, +1 : weak, +2 : moderate to +3 : strong (Fig. $1 \mathrm{C}, \mathrm{D}, \mathrm{E}, \mathrm{F}$ ). We also considered: range of intensity with the percentage of cell stained when the tumor was heterogeneous. When less than $10 \%$ of cell showed staining, it was scored as negative. Altogether, these data allowed to establish a semi-qualitative score calculated as following: $\%$ of cell (score 1$)+\%$ of cell $($ score 2$)+\%$ of cell $($ score 3$)=$ final score .

\subsection{Statistical analysis}

The analysis of the results involving the expression of the Aurora A protein and the various histological and clinical parameters were made by using the chi-square and regression linear performed with the program Statistical Package for Social Sciences (SPSS 13.0) and Epi info 6. We considered that results were statistically significant when $p$ values were $<0.05$, asterisks indicate $p<0.05\left(^{*}\right)$ and $p<0.01\left(^{* *}\right)$.

\section{Results}

Since antibody specificity is of great importance in immunohistochemistry, we analyzed the specificity of the Aurora A antibody prepared by the laboratory. The specificity of the Aurora A antibody was tested by western blot performed with recombinant Aurora A protein and cellular extracts. A single specific band was detected at $46 \mathrm{Kda}$ and $50 \mathrm{Kda}$ corresponding respectively to cellular and to recombinant protein (Fig. 2).

The invasive Ductal Carcinoma (DCIV) and the 'In Situ' (IS) tumors cells were analyzed along with the adjacent normal mammary tissue in 54 slides, but in most of the cases only two types of tissues were available. Details concerning slides are in Table 2.

Using the autologous antibody, Aurora A protein expression was tested by IHC on breast tissue. Overexpression was observed in $92.2 \%$ for Invasive Ductal Carcinoma (DCIV) and in $91.9 \%$ for 'In Situ' Ductal Carcinoma (IS). In the case of DCIV, Aurora A overexpression was observed in $83.2 \%$ of the cases in both nucleus and cytoplasm, while $4.2 \%$ in only nucleus and $12.6 \%$ in only cytoplasm. Whereas in IS the percentages are respectively: $79.3 \%, 3.5 \%$ and $17.2 \%$. The results present no significant differences between Aurora A expression and localization in DCIV and IS. 
Table 3

Comparison of Aurora A expression and localization in malignant and non malignant tissues

\begin{tabular}{lcc}
\hline Aurora A & Malignant & Non malignant \\
\hline Overexpression & $99[92.5 \%]$ & $77[84.6 \%] £$ \\
Negative expression & $8[7.5 \%]$ & $14[15.4 \%] £$ \\
Nuclear \& Cytoplasmic & $82[82.8 \%]$ & $37[48 \%] v$ \\
Nuclear Or Cytoplasmic & $17[17.2 \%]$ & $40[52 \%] v$ \\
Only Nuclear & 4 & 8 \\
Only cytoplasmic & 13 & 32 \\
\hline
\end{tabular}

$£: p=0.07 . v: p=0.000001^{* *}, \mathrm{OR}=5.21, \mathrm{RR}=2.31$.

Table 4

Association between Aurora A expression in malignant tissue and pathologic parameters

\begin{tabular}{lc}
\hline Pathologic parameters & Aurora A expression \\
& $p$ \\
\hline Age & 0.30 \\
SBR & 0.06 \\
Tumor size & 0.20 \\
RE & 0.26 \\
RP & $0.01^{*}$ \\
Nodal status & $0.02^{*}$ \\
Nuclear grade & $0.02^{*}$ \\
Mitotic index & 0.37 \\
\hline
\end{tabular}

Altogether, the tumoral tissue has protein overexpression in $92.5 \%$ (Table 3). When it was possible, the normal adjacent mammary tissues were included in the study and we observed a weak and a moderate but not a strong Aurora A expression in non malignant breast tissue with a rate of $84.6 \%$ (Fig. 1G). No significant differences between Aurora A expression in malignant and non malignant tissue is observed $p=0.07$, even if this protein seems less frequently expressed in non malignant tissue (Table 3).

The subcellular localization of the protein in malignant tissue was both cytoplasmic and nuclear (Fig. 1F) in $82.8 \%$ of the cases. In $4.1 \%$ of the cases the expression observed was only nuclear and in $13.1 \%$ was only cytoplasmic (Fig. 1D). In normal tissues the distribution of the protein was as follows: $48 \%$ nuclear and cytoplasmic, $41.6 \%$ cytoplasmic only and $10.4 \%$ nuclear only.

The Aurora A localization profile in both nucleus and cytoplasm is correlated with malignant tissue rather than with non malignant tissue $p=0.000001^{* *}, \mathrm{OR}=$ $5.21, \mathrm{RR}=2.31$; (Table 3 ).

The statistical study showed a correlation between a high Aurora A expression with an elevated nuclear grade $\left(p=0.021^{*}\right)$, as well as a low progesterone receptor positivity $\left(p=0.016^{*}\right)$. Finally we found an association between high Aurora A expression in malignant tissue and positive nodal status $\left(p=0.021^{*}\right)$ (Table 4).

\section{Discussion}

In this study, evidence has been provided for an overexpression of Aurora A in tumoral breast cancer tissue: DCIV and IS, in agreement with the previous studies [41,43-45]. The overexpression of this protein may be due to gene amplification which was reported in several studies $[23,24]$, but the increase in the rate of the protein may also be explained by the aberration of the degradation systems of this $\&^{2}$ kinase [12-15].

Only the work of Nadler et al. [41] mentioned the presence of the protein in the nucleus in breast cancer, the other authors found only a cytoplasmic localization. We found that this protein is often expressed in nucleus and cytoplasm at the same time. In our study, we obtained a relationship between a high expression of Aurora A kinase and an elevated nuclear grade on in agreement with the works of Royce et al. [45] and Nadler et al. [41], on the one hand, and with nodal status positivity as well as with low progesterone receptor expression in conformity with the works of Nadler et al., on the another hand. The relationship between Aurora A expression and nuclear grade is expected according to Aurora A function.

The overexpression of the Aurora A kinase by the non-malignant tissue was reported by Hoque et al. [44], but not by Tanaka et al. [43]. In this study, we find that non tumoral tissue overexpresses this protein at a frequency of $84.6 \%$. Thus observation goes to the logic of the malignant processing; the tissue being morphologically healthy could have already begun its cancerization process. Indeed, we observed correlation between tumoral and normal tissues from the same patient for the Aurora A expression. However, there are differences in protein localization observed between tumor and normal tissues, since the dual expression in nucleus and cytoplasm is associated with tumor. Less than $50 \%$ of normal tissue display such profile expression $p=0.000001^{* *}, \mathrm{OR}=5.21, \mathrm{RR}=2.31$. It is possible that the presence of the protein in both nuclear and cytoplasmic compartments corresponds to an early or established tumoral status. The shift of the protein from the cytoplasmic expression to simultaneously expression in both nucleus and cytoplasm can be explained by several mechanisms: taking into $\neq$ consideration that the STK15 gene amplification is reported in breast cancer in several studies [23,24], we can suggest that the alternative splicing is altered and could change the balance of the protein into nuclear isoforms during the transformation [31,47]. However it remains unclear how the splicing occurs in the context of gene amplifi- 
cation. From another point of view, during cancerization process, the cell begins its transformation by expressing cytoplasmic isoforms before acquiring a more aggressive aspect triggering the synthesis of the nuclear isoforms. We can also assume that the protein is expressed with all its isoforms as soon as the process of malignancy is initiated but remains healthy in appearance; however, when the protein is exported to the nucleus, the cell acquires a malignant phenotype. We can eventually propose that early in the malignant process, cell keeps an aberrant degradation system, which recognizes and destroys the nuclear isoforms; as the cancer process advances progressively; the degradation machinery of the protein no longer recognizes all of its isoforms [12-15] that is why the nuclear isoforms appear. Otherwise, we can also suppose that in cancer tissue, aurora A is differentially modified or regulated, leading to its mislocalization in the nucleus. We think that this result asks for more investigation, in order to better understand the shift in the subcellular localization during malignant transformation.

To recapitulate, we propose the following scenario: a first deregulation step in apparent healthy mammary tissue leads to a high level translation of Aurora A in the cytoplasm, in a second step, it is exported to nucleus; this process could be followed by a shift to tumor status which would be characterized by the presence of Aurora A protein in both nucleus and cytoplasm.

In fact, the overexpression and the localization of this protein should be evaluated in order to be used as a tool of early screening even before the cell and tissue change their morphology and earlier than the first stage of cancer is evident in histology. The screening of this pathology uses mammography with Magnetic Resonance Imaging (MRI) [48] or Ultrasound (US) when the patient has a dense breast tissue $[49,50]$. In addition, we need to analyze a "real" normal mammary tissue from healthy women and make a long-term survey to inspect the upcoming of every found profile. Since Aurora A is present in a normal cell only during the G2 and Mitosis phases, and does not exist in quiescent cells [51,52], it would be interesting to understand its mechanisms of deregulation during carcinogenesis.

\section{Acknowledgements}

The research was supported in part by Tunisian State Secretariat for Research and Technology.

\section{References}

[1] Sen S, Zhou H, White RA. A putative serine/threonine kinase encoding gene BTAK on chromosome $20 \mathrm{q} 13$ is amplified and overexpressed in human breast cancer cell lines, Oncogene 14(18) (1997), 2195-2200.

[2] Kollareddy M, Dzubak P, Zheleva D et al. Aurora kinases: Structure, functions and their association with cancer, Biomed Pap Med Fac Univ Palacky Olomouc Czech Repub 152(1) (2008), 27-33.

[3] Saeki T, Ouchi M, Ouchi T. Physiological and oncogenic Aurora-A pathway. Int J Biol Sci 5(7) (2009), 758-762.

[4] Barr A R, Gergely F. Aurora-A: the maker and breaker of spindle poles, J Cell Sci 120 (2007), 2987-2996.

[5] Liu Q, Ruderman JV. Aurora A, mitotic entry and spindle bipolarity. Proc Natl Acad Sci U S A 103(15) (2006), 58115586.

[6] Sasai K, Parant JM, Brandt ME et al. Targeted disruption of Aurora A causes abnormal mitotic spindle assembly, chromosome misalignment and embryonic lethality, Oncogene 27 (2008), 4122-4127.

[7] Marumoto T, Honda S, Hara T et al. Aurora-A kinase maintains the fidelity of early and late mitotic events in HeLa cells. J Biol Chem 278(51) (2003), 51786-51795.

[8] Kimura M, Kotani S, Hattori T et al. Cell cycle-dependent expression and spindle pole localization of a novel human protein kinase, Aik, related to Aurora of Drosophila and yeast Ipl1. J Biol Chem 272(21) (1997), 13766-13771.

[9] Glover DM, Leibowitz MH, McLean DA et al. Mutations in aurora prevent centrosome separation leading to the formation of monopolar spindles, Cell 81(1) (1995), 95-105.

[10] Fu J, Bian M, Jiang Q, Zhang C. Roles of Aurora kinases in mitosis and tumorigenesis. Mol Cancer Res 5(1) (2007), 1-10.

[11] Van Horn R D, Chu S, Fan L et al. Cdk1 Activity Is Required for Mitotic Activation of Aurora A during G2/M Transition of Human Cells. J Biol Chem 285(28) (2010), 21849-21857.

[12] Lim SK, Gopalan G. Aurora-A kinase interacting protein 1 (AURKAIP1) promotes Aurora-A degradation through an alternative ubiquitin-independent pathway, Biochem J 403(1) (2007), 119-127.

[13] Castro A, Arlot-Bonnemains Y, Vigneron S et al. APC/FizzyRelated targets Aurora-A kinase for proteolysis, EMBO Rep 3(5) (2002), 457-462.

[14] Pfleger CM, Kirschner MW. Identification of a new APC/C recognition domain, the A box, which is required for the Cdh1dependent destruction of the kinase Aurora-A during mitotic exit, Genes Dev 14 (2000), 655-659.

[15] Honda K, Mihara H, Kato Y et al. Degradation of human Aurora2 protein kinase by the anaphasepromoting complexubiquitin-proteasome pathway, Oncogene 19 (2000), 28122819.

[16] Li J J, Li S A. Mitotic kinases. The key to duplication, segregation and cytokinesis errors, chromosomal instability and oncogenesis, Pharmacol Ther 111 (2006), 974-984.

[17] Schvartzman J M, Sotillo R, Benezra R. Mitotic chromosomal instability and cancer. mouse modelling of the human disease, Nat Rev Cancer 10(2) (2010), 102-115.

[18] Shang-bin Y, Xiao-bo Z, Hong-xia Z et al. Amplification and overexpression of Aurora-A in esophageal squamous cell carcinoma, Oncol Rep 17(2007), 1083-1088.

[19] De Angelis PM, Stokke T, Beigi M et al. Chromosomal 20q gain in the DNA diploid component of aneuploid colorectal carcinomas, Int J Cancer 120 (2007), 2734-2738. 
[20] Dimovaa I, Yosifovaa A, Zaharievaa B et al. Association of 20q13.2 copy number changes with the advanced stage of ovarian cancer-tissue microarray analysis, Eur J Obstet Gynecol Reprod Biol 118(1) (2005), 81-85.

[21] Buffart T E, Van Grieken N C T, Tijssen M et al. High resolution analysis of DNA copy-number aberrations of chromosomes 8, 13, and 20 in gastric cancers, Virchows Arch 455(2009), 213-223.

[22] Klein A, Reichardt W, Jung V et al. Overexpression and amplification of STK15 in human gliomas, Int J Oncol 25(6) (2004), 1789-1794

[23] Staff S, Isola J, Jumppanen M et al. Aurora-A gene is frequently amplified in basal-like breast cancer, Oncol Rep 23(2) (2010), 307-312.

[24] Bodvarsdottir SK, Hilmarsdottir H, Birgisdottir V et al. Aurora-A amplification associated with BRCA2 mutation in breast tumours, Cancer Lett 248 (2007), 96-102.

[25] Baldini E, Arlot-Bonnemains Y, Mottolese M et al. Deregulation of Aurora kinase gene expression in human testicular germ cell tumours, Andrologia 42(4) (2010), 260-267.

[26] Zhang W, Wang J, Liu SJ, Hua W, Xin XY. Correlation between Aurora-A expression and the prognosis of cervical carcinoma patients, Acta Obstet Gynecol Scand 88(5) (2009), 521-527.

[27] Milam M R, Gu J, Yang H, Celestino J, Wu W, Irwin B H et al. STK15 F31I polymorphism is associated with increased uterine cancer risk. A pilot study, Gynecol Oncol 107 (2007), 71-74.

[28] Makoto T K, Takahiro M, Jeffrey C, Norma J N, Susumu S, Katsuyuki Tet al. Two Functional Coding Single Nucleotide Polymorphisms in STK15 (Aurora-A) Coordinately Increase Esophageal Cancer Risk, Cancer Res 65(9) (2005), 35483554.

[29] Matarasso N, Bar-Shira A, Rozovski U, Rosner S, OrrUrtreger A. Functional analysis of the Aurora Kinase A Ile31 allelic variant in human prostate, Neoplasia 9(9) (2007), 707715.

[30] Reiter R, Gais P, Jütting U, Steuer-Vogt MK, Pickhard A, Bink $\mathrm{K}$, et al. Aurora kinase A messenger RNA overexpression is correlated with tumor progression and shortened survival in head and neck squamous cell carcinoma. Clin Cancer Res 12(17) (2006), 5136-5141.

[31] Kimura MT, Mori T, Conroy J, Nowak NJ, Satomi S, Tamai K et al. Two functional coding single nucleotide polymorphisms in STK15 (Aurora-A) coordinately increase esophageal cancer risk. Cancer Res 65(9) (2005), 3548-3554.

[32] Vidarsdottir L, Bodvarsdottir S K, Hilmarsdottir H, Tryggvadottir L, Eyfjord J. Breast cancer risk associated with AURKA 91T/A polymorphism in relation to BRCA mutations, Cancer Lett 250 (2007), 206-212.

[33] Ogawa E, Takenaka K, Katakura H, Adachi M, Otake Y, Toda $\mathrm{Y}$ et al. Perimembrane Aurora-A expression is a significant prognostic factor in correlation with proliferative activity in non-small-cell lung cancer (NSCLC), Ann Surg Oncol 15(2) (2008), 547-554.

[34] Mazumdar A, Henderson YC, El-Naggar AK, Sen S, Clayman GL. Aurora kinase A inhibition and paclitaxel as targeted combination therapy for head and neck squamous cell carcinoma, Head Neck 31(5) (2009), 625-634.

[35] Yang G, Chang B, Yang F, Guo X, Cai KQ, Xiao XS et al. Aurora kinase A promotes ovarian tumorigenesis through dys- regulation of the cell cycle and suppression of BRCA2, Clin Cancer Res 16(12) (2010), 3171-3181.

[36] Lassus H, Staff S, Leminen A, Isola J, Butzow R. Aurora-A overexpression and aneuploidy predict poor outcome in serous ovarian carcinoma, Gynecol Oncol 120(1) (2011), 11-17.

[37] Cammareri P, Scopelliti A, Todaro M, Eterno V, Francescangeli F, Moyer MP et al. Aurora-A is essential for the tumorigenic capacity and chemoresistance of colorectal cancer stem cells, Cancer Res 70(11) (2010), 4655-4665.

[38] Qu Y, Zhang L, Mao M, Zhao F, Huang X, Yang C et al. Effects of DNAzymes targeting Aurora kinase A on the growth of human prostate cancer, Cancer Gene Ther 15(8) (2008), 517-525.

[39] Rojanala S, Han H, Munoz RM, Browne W, Nagle R, Von Hoff DD et al. The mitotic serine threonine kinase Aurora-2 is a potential target for drug development in human pancreatic cancer, Mol Cancer Ther 3(4) (2004), 451-457.

[40] Rugge M, Fassan M, Zaninotto G, Pizzi M, Giacomelli L, Battaglia $\mathrm{G}$ et al. Aurora kinase A in Barrett's carcinogenesis, Hum Pathol 41(10) (2010), 1380-1386.

[41] Nadler Y, Camp RL, Schwartz C, Rimm DL, Kluger HM, Kluger Y. Expression of Aurora A (but not Aurora B) is predictive of survival in breast cancer, Clin Cancer Res 14(14) (2008), 4455-4462.

[42] Xia LP, Zhou FF, Yang MT, Liu Q. Roles of Aurora-A in tumorigenesis and prognosis of breast cancer, Chin J Cancer 28(6) (2009), 668-672.

[43] Tanaka T, Kimura M, Matsunaga K, Fukada D, Mori H, Okano Y. Centrosomal kinase AIK1 is overexpressed in invasive ductal carcinoma of the breast, Cancer Res 59 (1999), 2041-2044.

[44] Hoque A, Carter J, Xia W, Hung MC, Sahin AA, Sen S et al. Loss of aurora A/STK15/BTAK overexpression correlates with transition of in situ to invasive ductal carcinoma of the breast, Cancer Epidemiol Biomarkers Prev 12(12) (2003), 1518-1522.

[45] Royce ME, Xia W, Sahin AA, Katayama H, Johnston DA, Hortobagyi G et al. STK15/Aurora-A expression in primary breast tumors is correlated with nuclear grade but not with prognosis, Cancer 100(1) (2003), 12-19.

[46] Cremet J Y, Descamps S, Vérité F, Martin A, Prigent C. Preparation and characterization of a human aurora-A kinase monoclonal antibody, Mol Cell Biochem 243 (2003), 123-131.

[47] Tatsuka M, Sato S, Kanda A, Miki T, Kamata N, Kitajima S et al. Oncogenic role of nuclear accumulated Aurora-A, Mol Carcinog 48(9) (2009), 810-820.

[48] Saslow D, Boetes C, Burke W, Harms S, Leach MO, Lehman $\mathrm{CD}$ et al. American cancer society guidelines for breast screening with MRI as an adjunct to mammography, CA Cancer $J$ Clin 57(2) (2007), 75-89.

[49] Berg Wendie. A Tailored Supplemental Screening for Breast Cancer: What Now and What Next? AJR Am J Roentgenol 192(2) (2009), 390-399.

[50] Ravert PK, Huffaker C. Breast cancer screening in women: An integrative literature review, J Am Acad Nurse Pract 22(12) (2010), 668-673.

[51] Carmena M, Earnshaw W. The cellular geography of aurora kinases, Nat Rev Mol Cell Biol C 4(11) (2003), 842-854.

[52] Lindon C, Pines J. Ordered proteolysis in anaphase inactivates Plk1 to contribute to proper mitotic exit in human cells, $J$ Cell Biol 164(2) (2004), 233-241. 


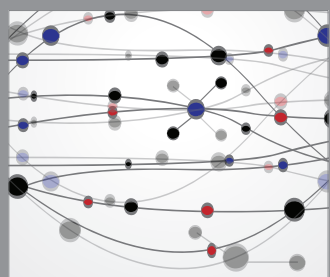

The Scientific World Journal
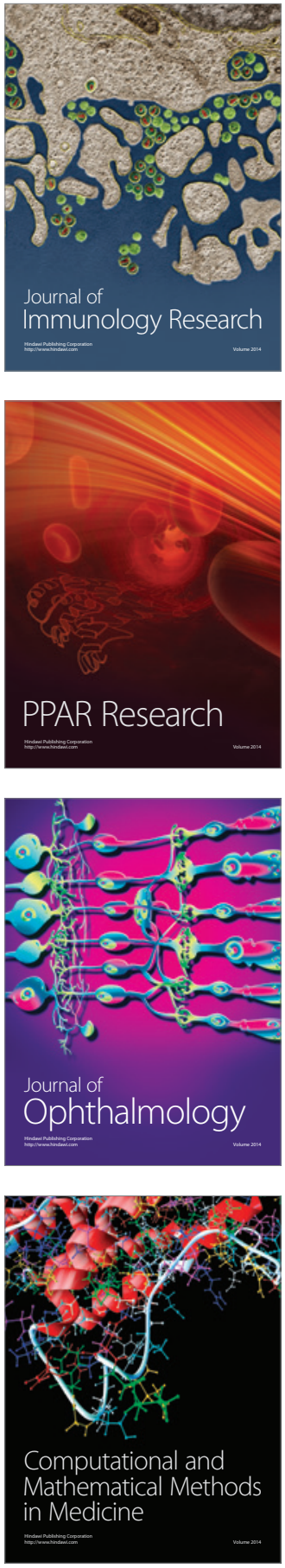

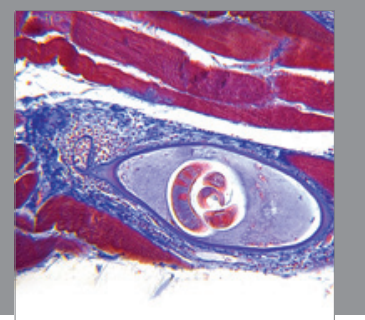

Gastroenterology

Research and Practice
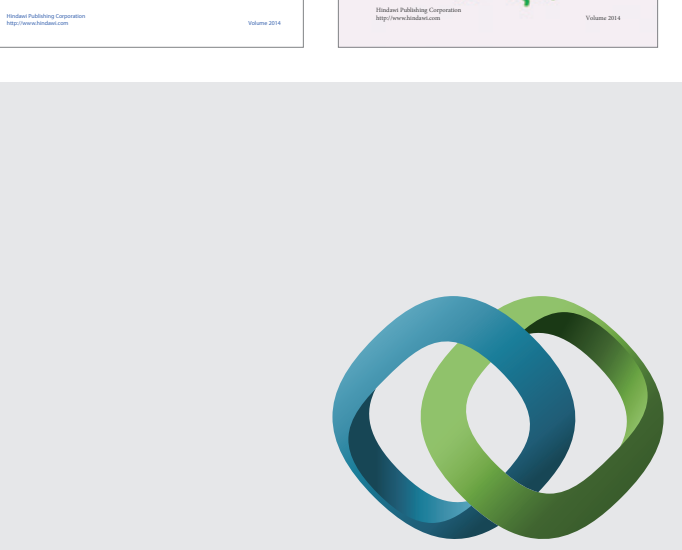

\section{Hindawi}

Submit your manuscripts at

http://www.hindawi.com
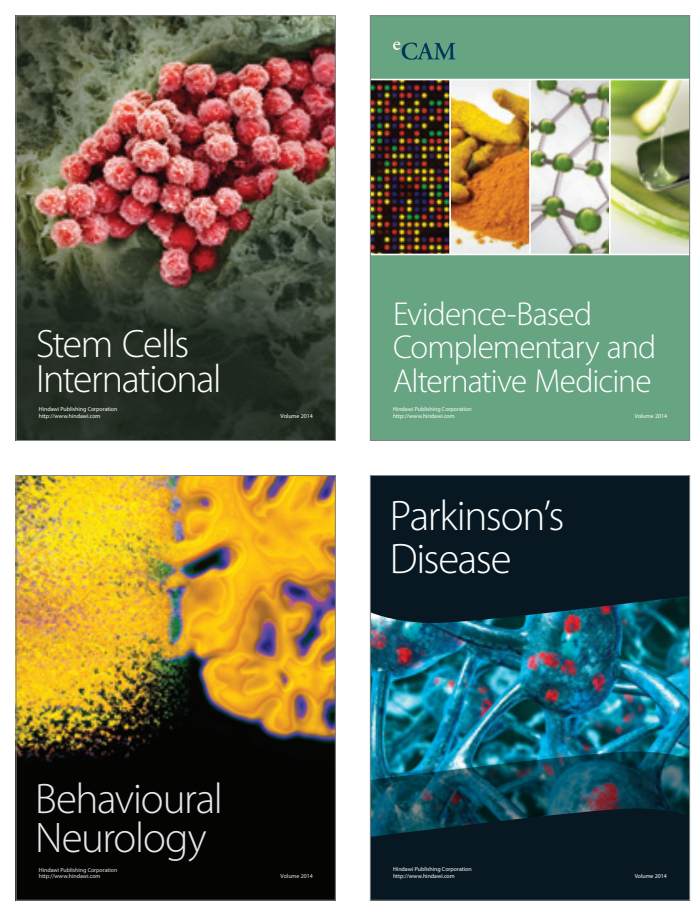

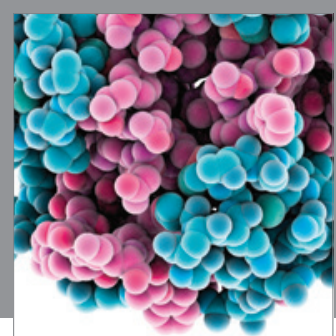

Journal of
Diabetes Research

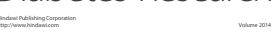

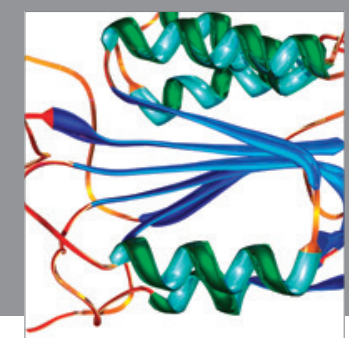

Disease Markers
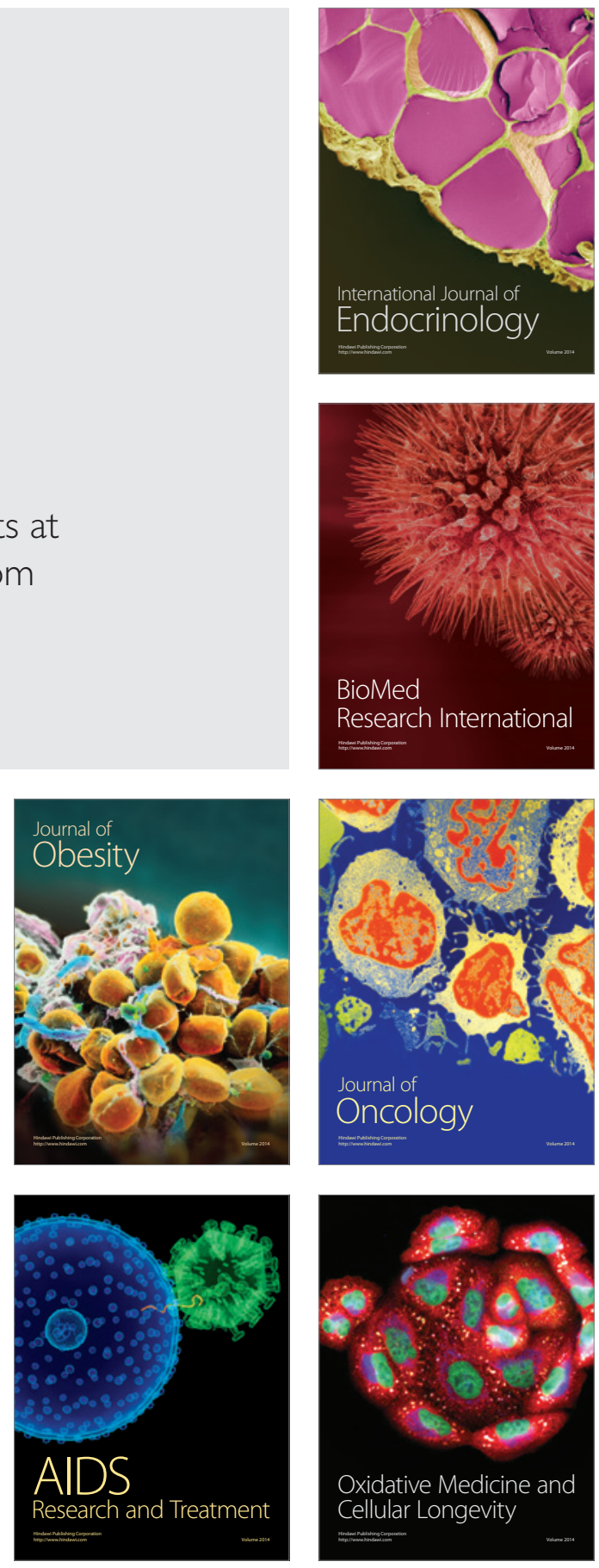